\title{
O envelhecimento na perspectiva de homens idosos ${ }^{1}$
}

\author{
Lilian Maria Borges Gonzalez $z^{2}$ \\ Universidade Católica de Brasilia, Brasília-DF, Brasil \\ Eliane Maria Fleury Seidl \\ Universidade de Brasilia, Brasilia-DF, Brasil
}

\begin{abstract}
Resumo: O envelhecimento bem-sucedido é um processo multidimensional, que envolve aspectos físicos, cognitivos, emocionais e sociais. O presente artigo, de caráter exploratório e descritivo, objetivou investigar percepções de homens idosos quanto às limitações e aos ganhos vinculados ao envelhecimento e aos fatores de proteção da saúde na velhice. Treze homens com idades superiores a 60 anos e níveis diversos de escolaridade responderam a entrevistas semiestruturadas e o conteúdo de suas respostas foi submetido à análise qualitativa. Sete subcategorias emergiram do eixo temático "resultados do envelhecimento", com destaque para as perdas físicas e os ganhos pessoais favorecidos pelo acúmulo de experiências. No eixo temático "saúde na velhice" foram categorizadas quatro medidas para melhoramento da saúde, com predomínio de respostas referentes à busca por serviços médicos e à adoção de estilo de vida saudável. Os participantes apresentaram uma visão biopsicossocial dos fatores relacionados ao envelhecer bem, embora com ênfase em aspectos biológicos.
\end{abstract}

Palavras-chave: idosos, envelhecimento, gênero, homens, desenvolvimento humano.

\section{Aging from the perspective of elderly men}

\begin{abstract}
A successful aging process is multidimensional and involves physical, cognitive, emotional and social factors. This exploratory and descriptive study investigated the perceptions of elderly men concerning limitations and gains related to the aging process and protective factors in old age. Thirteen men older than 60 years of age with varied levels of education participated in semi-structured interviews and their answers were submitted to qualitative analysis. Seven subcategories emerged from the thematic axis "results of aging", with an emphasis on physical losses and personal gains favored by the accumulation of experiences. In the thematic axis "health in old age" four measures to improve health were categorized, with a predominance of answers related to the search of medical services and the adoption of a healthy lifestyle. The participants presented a biopsychosocial perspective of factors related to aging well though with an emphasis on biological variables.
\end{abstract}

Keywords: aged, aging, gender, men, human development.

\section{El envejecimiento bajo la perspectiva de hombres ancianos}

Resumen: El envejecimiento exitoso es un proceso multidimensional que involucra a aspectos físicos, cognitivos, emocionales y sociales. Este trabajo, de carácter exploratorio y descriptivo, verificó percepciones de hombres ancianos respecto a limitaciones y beneficios vinculados al envejecimiento y a factores de protección de salud en la vejez. Trece hombres con edad superior a 60 años, de diferentes niveles de escolaridad, participaron de entrevistas semi-estructuradas, siendo el contenido de sus respuestas sometido al análisis cualitativo. Siete subcategorías surgieron del eje temático "resultados del envejecimiento", dando énfasis a perdidas físicas y ganancias individuales favorecidas por experiencias acumuladas. En el eje temático "salud en la vejez", fueron clasificadas cuatro medidas para el mejoramiento de la salud, con predominio de respuestas relativas a búsqueda por servicios médicos y adopción de un estilo de vida saludable. Los participantes presentaron una visión biopsicosocial de los factores relacionados a envejecer bien aunque con énfasis en variables biológicas.

Palabras clave: adultos mayores, envejecimiento, género, hombres, desarrollo humano.

A velhice é marcada por fatores biopsicossociais, constituindo, ao mesmo tempo, uma realidade biológica e psicológica e uma construção sociocultural. Se, por um lado, é decorrente de um processo progressivo de modificações fisiológicas e funcionais, por outro é também representada e vivenciada de formas diversas nos diferentes contextos culturais. Nesse período do curso de vida, ocorrem várias transformações importantes, como risco aumentado de doenças, perdas sensoriais e cognitivas, alterações na aparência física

\footnotetext{
${ }^{1}$ Este texto foi revisado seguindo o Acordo Ortográfico da Língua Portuguesa (1990), em vigor a partir de $1^{\circ}$ de janeiro de 2009.

${ }^{2}$ Endereço para correspondência:

Lilian Maria Borges Gonzalez. Av. Pau Brasil, Lote 5/apto. 905. CEP

71.916-500. Águas Claras-DF, Brasil. E-mail: limaborgesg@gmail.com
}

e mudanças de papéis e status sociais. O envelhecimento e a velhice constituem, portanto, experiências heterogêneas e, como tal, devem ser abordados em toda a complexidade e variabilidade que os caracterizam (Berger, 2003; Schneider \& Irigaray, 2008).

A perspectiva teórica do life span (ou ciclo vital), no estudo das constâncias e mudanças que ocorrem da concepção à morte, pressupõe que o processo de desenvolvimento acarreta uma dinâmica entre ganhos (crescimento) e perdas (declínio), ressaltando a plasticidade intraindividual que designa o potencial para diferentes formas de comportamento e desenvolvimento no curso da vida. Envelhecer bem, nessa perspectiva, depende de múltiplas variáveis e está relacionado à história individual, ao contexto histórico-cultural e a fatores genético-biológicos (Baltes, 1987). 
As pesquisas acerca do envelhecimento, no entanto, até meados do século passado, superestimavam as perdas que ocorrem nesse processo. Déficits cognitivos e fisiológicos associados com a idade eram comumente interpretados pelos pesquisadores como determinados exclusivamente pela idade, sem considerar que muitos declínios que ocorrem na idade adulta avançada podem ser explicados em termos, por exemplo, de estilo de vida e hábitos inadequados (Rowe \& Kahn, 1987). Desde então, observa-se um crescente reconhecimento da heterogeneidade do envelhecimento e, consequentemente, o interesse em estabelecer parâmetros de comparação entre o envelhecimento usual e o envelhecimento bem-sucedido e em identificar as variáveis fisiológicas e psicossociais associadas ao envelhecer bem (Cupertino, Rosa, \& Ribeiro, 2007; Rowe \& Kahn, 1987; Teixeira \& Neri, 2008). O conhecimento desses fatores possibilita elaborar políticas e programas na área e, assim, evitar ou adiar alterações patológicas, de modo a amenizar os altos custos sociais da velhice disfuncional.

Entretanto, ainda nos dias atuais, não há uma definição consensual para o envelhecimento bem-sucedido, o qual tem sidoreferido pordiversos outros termos, comoenvelhecimento ativo, robusto e saudável (Teixeira \& Neri, 2008). Uma velhice bem-sucedida, em linhas gerais, resulta da harmonia entre as perdas naturais do envelhecimento e as capacidades remanescentes, ou seja, depende do delicado equilíbrio entre as limitações e as potencialidades do indivíduo à medida que este envelhece (Neri, Yassuda, \& Cachioni, 2004). O termo envelhecimento ativo foi adotado pela World Health Organization (WHO, 2005, p. 13), no final da década de 1990, para designar "o processo de otimização das oportunidades de saúde, participação e segurança, com o objetivo de melhorar a qualidade de vida à medida que as pessoas ficam mais velhas".

Por conseguinte, além da longevidade e da manutenção de um bom estado de saúde física e do baixo risco de doenças, envelhecer bem está associado à participação na comunidade, ao engajamento ativo com a vida, ao bem-estar subjetivo, bem como à manutenção da autonomia e do máximo de independência possível (Rowe \& Kahn, 1997; Teixeira \& Neri, 2008; WHO, 2005). Uma revisão de literatura foi conduzida por Peel, McClure e Bartlett (2005) com a finalidade de levantar os determinantes comportamentais do envelhecimento saudável. De modo geral, os oito estudos selecionados e analisados pelos autores enfatizaram a manutenção de independência funcional, o alto desempenho físico, as habilidades cognitivas e a ausência de doenças e de morbidade psiquiátrica como componentes do envelhecimento saudável. Dos determinantes comportamentais associados, isoladamente ou em combinação, com o envelhecimento saudável, prevaleceram não fumar, estar fisicamente ativo, manter peso adequado e consumir álcool moderadamente.

Além do emprego de medidas objetivas na investigação dos componentes do envelhecimento bem-sucedido, nos últimos anos têm aumentado estudos direcionados para o conhecimento das percepções dos próprios idosos acerca do que é necessário para adaptar-se às perdas e maximizar os ganhos decorrentes do envelhecimento e, dessa forma, envelhecer de modo ideal ou saudável (Cupertino e cols., 2007; Teixeira \& Neri, 2008). Com esse propósito, Cupertino e cols., por exemplo, entrevistaram 501 idosos com idade entre 60 e 93 anos sobre a definição de envelhecimento saudável e a forma de alcançá-lo. As respostas dos participantes possibilitaram aos autores a elaboração de 29 categorias referentes ao envelhecimento saudável. As categorias mais apontadas pelos participantes foram saúde física, saúde social, saúde emocional, preocupação com alimentação/exercícios e evitar fatores de risco. As respostas evidenciaram diferenças de gênero, havendo uma tendência das mulheres em citar mais do que os homens as categorias saúde social, saúde emocional, ter fé/espiritualidade, manter espírito jovem e integridade, o que evidenciou maior preocupação das mulheres com o bem-estar emocional em relação aos homens. Estes destacaram outros fatores, como a estabilidade financeira. A categoria não guardar mágoas apareceu apenas no relato das mulheres.

A saúde e a qualidade de vida na velhice são influenciadas também por questões de cultura e gênero (WHO, 2005), tendo em vista que as diferenças entre homens e mulheres não decorrem apenas de variáveis biológicas, mas resultam ainda de construções sócio-histórico-culturais que levam à manifestação de atitudes, a padrões de comportamento e a valores passíveis de favorecer ou prejudicar o alcance do envelhecimento bem-sucedido (Braz, 2005; Gomes \& Nascimento, 2006; Zunzunegui, Alvarado, Béland \& Vissandjee, 2009).

$O$ gênero foi uma das variáveis abordadas em estudo conduzido por Ribeiro, Neri, Cupertino e Yassuda (2009) com o objetivo de investigar o engajamento de 155 idosos residentes na comunidade quanto à prática de atividades físicas e instrumentais e à participação em atividades sociais e intelectuais. As análises comparativas permitiram verificar um perfil diferente de estilo de vida ativo entre os gêneros. Diferenças significativas foram observadas quanto à frequência de realização de atividades físicas e atividades ocupacionais, com atividades físicas sendo mais frequentemente realizadas pelos homens e as atividades ocupacionais (instrumentais, sociais e intelectuais) mais comuns entre as mulheres. De acordo com as autoras, esses resultados, embora não permitam generalizações, mostram o imperativo de atentar para a distinção entre os gêneros em relação aos padrões diferentes de envelhecimento ativo e de preferência por tipos de atividade.

Em outro trabalho realizado com 20 idosos de ambos os sexos participantes de um programa para a terceira idade, Figueiredo e cols. (2007) constataram que os homens evidenciaram baixa autoestima ao envelhecerem, ao contrário das mulheres, que relataram conquista de autonomia, liberdade e aprendizado com o avançar da idade. De acordo com os autores, a baixa autoestima vivenciada pelos 
homens idosos parece atrelada a certas condições vivenciadas no processo de envelhecimento, como o acometimento por doenças crônicas e a aposentadoria, que podem implicar perda ou diminuição de aspectos bastante valorizados na socialização dos homens, incluindo poder, autonomia econômica e liberdade.

As questões de gênero, portanto, não podem ser ignoradas pelos profissionais de saúde nem podem ser tratadas, conforme ressalta Figueiredo e cols. (2007), apenas por estudos estatísticos e demográficos, requerendo também a condução de estudos qualitativos capazes de melhor abordar a complexidade social da relação entre gênero, envelhecimento e saúde. Nesse campo de inter-relação entre envelhecimento e gênero, vários autores destacam a premência de se promover investigações acerca da posição social específica de homens e mulheres idosos e das repercussões em seus comportamentos e status de saúde (por exemplo, Fletcher, Higginbotham, \& Dobson, 2002; Gomes \& Nascimento, 2006; Keene \& Li, 2005; Schraiber, Gomes, \& Couto, 2005). É nessa linha de investigação que se situa esta pesquisa, realizada no intuito de abordar o processo de desenvolvimento masculino com foco na investigação e análise qualitativa das percepções de homens idosos em relação ao próprio envelhecimento e aos fatores de proteção e manutenção da saúde na velhice.

\section{Método}

\section{Participantes}

A pesquisa foi conduzida com treze homens residentes no Distrito Federal, todos casados e com idades entre 61 e 81 anos $(M=67,2)$, sendo o idoso-jovem (60 a 69 anos) a faixa etária predominante (77\%). Em sua maioria, estavam aposentados $(69,2 \%)$ e tinham níveis de escolaridade variando entre fundamental incompleto $(53,8 \%)$, médio completo $(22,7 \%)$ e superior completo (23\%). Entre os tipos de serviço ainda exercidos ou anteriores à aposentadoria estavam serviços gerais de obra (30\%), serviços autônomos (23\%), serviço público $(23 \%)$, serviços rurais $(15,4 \%)$, serviço militar $(15,4 \%)$ e docência de nível superior $(7,7 \%)$. Todos os entrevistados referiram pelo menos um agravo à saúde, com predomínio de hipertensão arterial $(53,8 \%)$ e diabetes $(30,8 \%)$, mas não possuíam, de acordo com os critérios de exclusão do estudo, prejuízos em capacidades funcionais e cognitivas. Dois dos participantes haviam sido acometidos por câncer de próstata, mas relataram a remissão da doença.

\section{Instrumento}

$\mathrm{Na}$ coleta dos depoimentos dos participantes foi empregado um roteiro de entrevista semiestruturado, elaborado com base nos objetivos da pesquisa. A primeira parte do roteiro foi constituída por questões destinadas ao levantamento de dados sociodemográficos, como idade, estado civil, nível de escolaridade e situação empregatícia. Outras cinco perguntas abertas foram elaboradas com a finalidade de identificar limitações e ganhos atribuídos pelos participantes ao processo de envelhecimento, assim como de investigar as estratégias consideradas necessárias para lidar com tais alterações e promover saúde na velhice.

\section{Procedimentos}

\section{Coleta de dados}

O recrutamento dos participantes foi feito por conveniência, pela primeira autora, em diferentes contextos sociais, por meio da abordagem a pessoas da comunidade com o gênero e o limite de idade pretendidos e que possuíam suas capacidades funcionais preservadas. No contato inicial com os idosos, pessoalmente ou por telefone, foi feito o convite para participação no estudo e realizado o agendamento da entrevista em dia, horário e local convenientes aos envolvidos. Concluída a primeira etapa, a entrevista foi conduzida em uma sala de uma universidade privada ou na residência do participante, de modo individual e com base no roteiro pré-elaborado. As respostas fornecidas foram gravadas em áudio e, a seguir, integralmente transcritas de modo a favorecer a análise dos dados.

Com a constatação de repetições nas verbalizações dos participantes, por ocasião da décima terceira entrevista, o número de depoimentos colhidos foi considerado suficiente, tendo em vista o critério de saturação e o tipo de análise qualitativa pretendida no estudo.

\section{Análise dos dados}

As informações reunidas foram organizadas e analisadas de acordo com os pressupostos da análise de conteúdo (Bardin, 1977/2002), que possibilitam categorizar as mensagens dos participantes segundo a identificação de similaridades e convergências ou de ambiguidades e contradições em seus relatos. Parte-se de uma pré-análise e da exploração e organização do material coletado para se alcançar a elaboração de categorias de significação e, assim, possibilitar a interpretação dos resultados.

\section{Considerações éticas}

No encontro com cada participante, foram feitos esclarecimentos sobre a pesquisa e foi apresentado o Termo de Consentimento Livre e Esclarecido, que foi lido, explanado e assinado em duas vias antes do início da entrevista, conforme previsto em projeto correspondente aprovado pelo Comitê de Ética em Pesquisa da Universidade Católica de Brasília (Processo CEP/UCB 194/2009). A participação voluntária na pesquisa foi assegurada e preservou-se o sigilo quanto à identidade dos entrevistados, aos quais foram atribuídos nomes fictícios. 


\section{Resultados e Discussão}

Dois eixos temáticos foram identificados no relato verbal dos participantes, de acordo com as questões contempladas no roteiro de entrevista, a saber: (1) resultados do envelhecimento, concernente à avaliação das decorrências do próprio envelhecimento avançado ou de fenômenos a ele associados (por exemplo: aposentadoria e adoecimento), abarcando a atribuição do sentido de perda ou de ganho às mudanças ocorridas nesse processo; (2) saúde na velhice, concernente aos comportamentos dos idosos, em geral, que atuam de modo a favorecer ou a dificultar o alcance de níveis satisfatórios de saúde e de qualidade de vida no último estágio do ciclo de vida.

\section{Resultados do envelhecimento}

No primeiro eixo temático, foram identificadas as categorias limitações, vantagens e manutenções, as quais foram desdobradas em treze subcategorias. As limitações do envelhecimento foram referentes a mudanças no organismo caracterizadas por declínios no funcionamento fisiológico, com consequente redução de capacidades e atividades, e incluíram dois tipos de desvantagens: perdas físicas - relacionadas à diminuição do vigor, da agilidade, da resistência, da força muscular e/ou da atividade sexual se comparadas a outras etapas da vida, como dificuldades para caminhar rápido e para realizar serviços que requerem grande dispêndio físico - e perda de saúde - definida como maior ocorrência de problemas de saúde com suas implicações e maior dificuldade de recuperação em relação às pessoas mais jovens.

As perdas físicas foram prevalentes, sendo apontadas por onze dos participantes, em concordância com os resultados constatados no estudo de Cupertino e cols. (2007). Em suas palavras: "Todas as desvantagens do envelhecimento é (sic) a degenerescência física" (Paulo, 62 anos); "Tudo que vai fazer hoje é mais difícil do que quando a gente era mais novo. É mais cansaço, a força é menos, o fôlego é mais curto" (José, 67 anos). Os idosos com maior poder aquisitivo, histórico de trabalho intelectualizado e nível mais elevado de escolaridade destacaram as consequências das limitações físicas como comprometedoras do desempenho em atividades e exercícios físicos, tais como correr, caminhar e praticar esportes, avaliados como importantes para o bem-estar. De acordo com Ivo (62 anos), "A limitação é na parte física mesmo. Quem correu, quem jogou futebol, nadou e tudo mais, remou... então hoje a gente já não pode fazer tudo isso. Justamente a gente não caminha como caminhava antigamente, não se corre mais".

Por outro lado, os idosos de menor poder aquisitivo e com baixa escolaridade pareceram ressentir-se mais da diminuição na capacidade para trabalhar e consequente baixa da produção, como ilustram os seguintes relatos: "O corpo está mais debilitado. Então já tem uma grande diferença, não produz igual, não tem nem jeito. A gente não tem mais a resistência que tinha antigamente. Eu trabalhava dia e noite, hoje em dia já não aguento mais fazer isso" (Mário, 61 anos); "Hoje se a gente for trabalhar a gente não dá conta, conforme o serviço, não dá conta de fazer o serviço que fazia" (Toni, 71 anos). A perda do ritmo de trabalho foi apontada por Veloz, Nascimento-Schulze e Camargo (1999) como uma representação tipicamente masculina sobre o envelhecimento, a qual se apoia na noção de atividade e enfatiza a lentidão na execução de atividades, o declínio na capacidade laboral e a perda da utilidade social da pessoa idosa.

No entanto, apesar da indicação de várias limitações de ordem física, alguns idosos relativizaram seu desempenho diminuído considerando as condições possíveis para sua faixa de idade. Nesse aspecto, Rui (64 anos), por exemplo, destacou que "o sexo também não é como quando eu era jovem. Mas a minha vida sexual é normal, dentro das minhas condições, da minha idade, do meu estado físico e psicológico".

Em menor destaque, foi mencionado pelos participantes o acometimento na velhice por doenças e dores, bem como a dificuldade de recuperação em casos de processos infecciosos ou traumáticos (perda de saúde). A esse respeito, Rui (64 anos) declara:

Não adianta você falar "eu tenho saúde" porque não tem. O idoso não tem a saúde que tinha quando não era idoso. Porque tem sempre uma dorzinha aqui, uma dorzinha ali, que demora mais doendo, não é como uma criança que leva uma pancada, você sopra e logo tá bom.

As doenças prevalentes entre os participantes foram hipertensão arterial e diabetes, que estão entre as enfermidades mais comumente diagnosticadas entre homens acima de 50 anos de idade (Issa, Fenter, Black, Grogg, \& Kruep, 2006; Laurenti, Jorge, \& Gotlieb, 2005). Como informado por Mario (61 anos): "Tenho problema seríssimo de diabetes (...) a gente vai tocando o barco conforme a maré. Você vê seu tipo de limitação e vê o que pode fazer". Contudo, outros idosos igualmente acometidos por enfermidades crônicas referiram controle de suas doenças e pequeno impacto do adoecimento sobre suas vidas, afirmando inclusive não se sentirem doentes, como foi o caso de Dílson (62 anos): "Eu sou diabético, mas eu faço um tratamento com a maior naturalidade possível e não considero isso nem como doença". Conforme Veras (2009), o idoso que mantém sua capacidade funcional, ou seja, que tem preservadas suas habilidades físicas e mentais para uma vida independente e autônoma, deve ser considerado um indivíduo saudável, ainda que seja acometido por uma ou mais doenças crônicas. Três participantes inclusive afirmaram que o adoecimento favoreceu-lhes uma conscientização maior a respeito da necessidade de cuidar da própria saúde e resultou em mudanças de hábitos que contribuíram para o alcance de uma melhor qualidade de vida: 
Antigamente, eu já era portador possivelmente desses dois problemas de saúde, primeiro diabetes e, em seguida, vim a ter o câncer de próstata. Eu hoje sabedor disso, eu vivo com uma qualidade de vida melhor. Eu bebia, hoje eu não bebo. São vários os procedimentos que eu faço hoje, que antigamente eu não fazia. (Dílson, 62 anos)

A ênfase atribuída pelos participantes às limitações orgânicas parece revelar a importância da limitação física para os homens, que fere o ideal masculino de força e resistência e pode comprometer a capacidade de produção e o desempenho sexual. Como verbalizado por Túlio (68 anos): "Acho difícil, acho ruim, pois não dou conta de fazer de tudo". De acordo com o modelo de masculinidade idealizado nas culturas ocidentais, ser homem é tido como ser ativo, provedor, forte, corajoso e com corpo resistente (Braz, 2005; Giffin, 2005; Gomes \& Nascimento, 2006). Além disso, a redução das capacidades fisiológicas de trabalho, muitas vezes associada a uma ou mais doenças crônicas, pode resultar na marginalização do idoso e na perda de sua condição social, considerando que as sociedades capitalistas privilegiam a produção.

A ausência de referências a alterações psicossociais ressaltadas em outros estudos (Bode \& Ridder, 2007; Carmel, 2001) possivelmente revela o fato de os entrevistados manterem em grande parte suas condições de vida familiar e social. Todos permaneciam casados e conviviam com a esposa, filhos e, às vezes, até netos. Como assinala Veras (1994), mais mulheres que homens vivenciam a solidão e a proporção de viuvez é muito maior entre elas. Além disso, os idosos demonstraram ter uma vida ativa e níveis elevados de independência e autonomia, apesar de a aposentadoria já ser uma realidade para uma parte deles e apesar do acometimento por doenças crônicas. As transformações na aparência física, como pele rugosa e flácida, também não foram incluídas no relato dos idosos. Culturalmente, uma imagem física condizente com o ideal de beleza da juventude é muito mais valorizada na mulher do que no homem. Alguns dos participantes referiram-se às mulheres como sendo mais vaidosas.

Se, por um lado, limitações resultantes do envelhecimento foram facilmente identificadas no depoimento dos participantes, por outro, também foram frequentes os relatos de vantagens associadas a esse processo inevitável da vida. As vantagens da maturidade foram relacionadas, em geral, à possibilidade de melhor compreender e agir no mundo, à transmissão dos saberes construídos a pessoas mais novas, à adoção de um estilo de vida mais saudável, ao usufruto de bens e direitos conquistados e à convivência com membros das novas gerações. Os ganhos apontados foram organizados em quatro categorias: ganhos pessoais (aprendizagem com erros e experiências do passado, possibilidade de prever acontecimentos e de ensinar os mais jovens em decorrência de uma maior compreensão da realidade, prudência no agir e/ou sensação de maior tranquilidade); ganhos sociais (convivência com novos membros da família, maior respeito por parte de outras gerações e direitos sociais assegurados aos idosos pelas políticas públicas); ganhos materiais (aposentadoria e bens adquiridos) e alterações no estilo de vida (mudanças no ritmo e modo de vida em comparação aos padrões de atividade e de comportamento adotados quando mais jovens, incluindo mudanças na rotina e de hábitos prejudiciais à saúde).

Para oito dos entrevistados, as vantagens do envelhecer estiveram relacionadas a ganhos pessoais. $\mathrm{O}$ acúmulo de experiências, conforme os depoimentos, possibilita maior discernimento e maior capacidade de previsão e de decisão diante dos acontecimentos: "Essa coisa clássica assim da experiência, basicamente eu diria da leniência, de você aceitar muito mais as coisas" (Paulo, 62 anos).

Essa é a vantagem que eu tenho, que a velhice pra mim trouxe, não fazer aquilo que eu fazia e agora eu vejo que era errado. Porque ai é o valor da idade, porque quando você vai ficando velho você vai sabendo mais o que deve fazer. (Rui, 64 anos)

Hoje eu imagino quanta bobagem que a gente fez por falta de experiência. Se a gente pudesse voltar no tempo, a vida seria bem mais tranquila. Eu acho que se compreende a vida melhor, se vive melhor baseado nessa experiência, a gente entende coisas que antigamente não se entendia. (Ivo, 62 anos)

A experiência acumulada ao longo dos muitos anos de vida foi descrita por alguns participantes como favorecedora não somente da resolução de questões pessoais, mas também do auxílio aos mais novos em suas buscas e decisões, tendo em vista a capacidade adquirida pelos mais velhos de diagnosticar e prever situações. Segundo João (68 anos): “Quando a gente vê um fato, um acontecimento, a gente já tem uma ideia do que vai ser, até palavras, atitudes, a gente já vai vendo o que tá acontecendo". Rui (64 anos), no entanto, ressentiu-se do pouco valor dado pelos mais jovens aos ensinamentos ofertados pelos idosos:

Eu posso até passar pra outra pessoa "olha não vai por aquele caminho não, que aquele caminho tem um precipício e você pode cair, porque eu já fui lá e testei”. Mas a juventude agora não acredita no idoso não. Finge que acredita, mas não acredita.

Ganhos sociais estiveram presentes no relato de quatro dos participantes, que apontaram o prazer de conviver com membros da nova geração familiar, o maior respeito adquirido junto aos mais novos e os direitos obtidos com as políticas em vigor. Por exemplo: "Só essa idade nos proporciona netos, os sobrinhos, quando jovem a gente não tem essas coisas boas. Talvez sejam esses os ganhos maiores" (Ivo, 62 anos);. "Eu sinto mais respeito por parte dos outros, a gente ganha 
mais respeito em filas e tudo. Os benefícios que foi (sic) muito bom. Sou muito grato a esses negócios que arrumaram pros idosos" (Mário, 61 anos).

Dois outros participantes destacaram ainda ganhos materiais oriundos do provimento da aposentadoria e de bens que se somaram ao patrimônio familiar. Juca (70 anos) é um deles: "Minhas economias, que eu vivo dos meus aluguéis e minha aposentadoria". Quatro idosos relataram mudanças importantes em seus estilos de vida com o avançar da idade, avaliadas por eles como geradoras de melhores condições de saúde e qualidade de vida: “Antes, quando eu era jovem, eu passava noites acordado em boates, coisa que hoje eu não faço porque eu sei que vai me prejudicar... Hoje, dez horas eu tô dormindo" (Rui, 64 anos); "A velhice nos trás uma maneira de viver mais tranquila, a gente se estressa menos. Acredito que o ganho maior hoje é em termos de paz de espírito e qualidade de vida" (Ivo, 62 anos); "Antigamente eu trabalhava dia e noite" (Mário, 61 anos).

Alguns participantes também indicaram manutenções no envelhecimento, relativas à existência de um nível adequado de funcionamento na velhice, com importantes capacidades remanescentes. Nesse sentido, destacou-se a preservação de capacidades cognitivas e de atividades, ainda que de forma compensatória e com maiores dificuldades. Por exemplo: "Minha memória não é fraca. Eu lembro muito, não esqueço, não sou daqueles que 'ih, eu me esqueci'. Não, isso aí ainda não chegou em mim. E eu tô fazendo tudo pra que não chegue (Rui, 64 anos); “O que eu fazia quando era jovem, hoje eu faço a mesma coisa, só que é menos um pouco" (Carlos, 69 anos).

Houve, em geral, menção a uma maior deterioração física em comparação ao funcionamento psicológico: "Eu acredito que mental a gente não envelhece. Acho que mentalmente dá pra conservar a jovialidade" (Ivo, 62 anos); "Eu não me sinto idoso, na minha cabeça não tem o idoso" (João, 68 anos).

As respostas dos entrevistados reproduziram representações sociais frequentes acerca das vantagens e limitações do envelhecer (Veloz e cols., 1999). A esse respeito, verifica-se grande ambivalência em relação aos significados socialmente atribuídos à velhice. Se, por um lado, ela é mencionada como merecedora de respeito pela experiência, sabedoria e responsabilidade individual conquistadas, por outro, é vista como sinônimo de incapacidades, doenças e perdas. No entanto, alguns idosos deram maior ênfase às vantagens advindas do envelhecer em comparação às suas limitações, conforme é perceptível no relato de Dílson (62 anos): “Ah, os ganhos são muito melhores, o que eu perdi, perdi, ficou pra trás. Não fico remoendo coisas 'ah, eu fiz isso'. Não, passado é passado”.

\section{Saúde na velhice}

No segundo eixo temático, as medidas para favorecimento da saúde sugeridas pelos participantes foram agrupadas em quatro subcategorias, referentes à busca por serviços de saúde, à adoção de estilo de vida ativo e saudável, à busca por informação e participação em atividades educativas, e ao cultivo de práticas espirituais e religiosas. No entanto, conforme ressaltado por Paulo (62 anos), a receita para viver bem a velhice é individual, depende muito de cada pessoa: "Quer dizer, o que é mais agradável para cada um, que pode ser mais confortável, que traga melhor bem-estar".

A busca por serviços de saúde apareceu na fala de todos os participantes como uma condição essencial para a manutenção do bem-estar na velhice. A indicação de visitas periódicas aos consultórios médicos com vistas ao acompanhamento de doenças já instaladas ou para identificação precoce de outras mostrou a ênfase dada à vulnerabilidade a doenças nesse estágio da vida, bem como apontou uma forte consideração às dimensões biológicas do envelhecimento saudável. Como exemplos de fala dessa subcategoria, destacam-se: "Em primeiro lugar, sem dúvida nenhuma, o cuidado médico. Esse é fundamental, porque não adianta se você está com doenças no organismo, doenças malresolvidas, não tem circunstância que melhore a qualidade de vida" (Paulo, 62 anos); "Um médico tem que acompanhar a saúde da gente, ir ao posto ou particular, fazer exames, não deixar de fazer, pois de repente pode aparecer diabetes ou outras doenças" (Silvio, 81 anos).

Por outro lado, houve também grande referência à adoção de estilo de vida promotor de melhores condições de saúde. Como exemplos de cuidados relacionados a essa subcategoria, apareceram prática de atividades físicas, consumo de alimentos saudáveis, moderação no consumo de sal e gordura, eliminação do uso de substâncias químicas e manejo do estresse. $\mathrm{Na}$ indicação dos participantes: "não exagerar em vários tipos de comida, comidas gordurosas, salgadas demais" (João, 68 anos); "fazer exercícios físicos, por exemplo, andar, natação e ter uma vida tranquila, não se preocupar muito" (Carlos, 69 anos); "evitar bebida alcoólica, o cigarro" (Pedro, 69 anos); "dormir, alimentar-se bem, ter um ritmo de vida assim de tranquilidade" (Toni, 71 anos).

Para Ivo (62 anos), o segredo de uma boa saúde na velhice está relacionado principalmente a uma vida com hábitos moderados e a eliminação dos excessos: "A pessoa tem que ter uma vida regrada, porque o que acaba com a saúde da pessoa são os excessos. Combatendo esses excessos nós entraríamos na prevenção". Rui (64 anos) enfatizou ainda a necessidade de manter-se ativo, de ter iniciativa e de dedicarse a novas atividades e projetos:

Não parar, continuar andando, pensando, continuar ou começar a fazer exercício físico. Isso melhora, com certeza melhora. Cair em campo. Ou seja, vai à luta. Parar de ficar jogando dominó, tirar o boné da cabeça, botar o sol na cabeça, jogar o dominó pra lá e vai andar, vai procurar o que fazer, sai da pracinha, sai de frente da televisão. 
A busca por informação e a participação em atividades educativas também foram avaliadas por alguns entrevistados como uma possibilidade de melhorar as condições de vida e de saúde dos idosos. Por exemplo: "eu acredito no que se refere às pessoas de uma idade mais avançada, que é o esclarecimento. Acho que a palavra-chave seria informação. Então eu acho que seria isso, levar informação, principalmente em forma de grupo" (Ivo, 62 anos); "Viver atualizado. Nós temos aí... televisão nem tanto, mas internet, se bem trabalhado é um excelente equipamento pra gente tirar dúvidas" (Dílson, 62 anos).

Nesse sentido, os grupos psicoeducativos têm potencial para promover aos idosos a possibilidade de estabelecer interações significativas e de adquirir comportamentos promotores de saúde. Witter (2006) destaca a necessidade de os idosos serem devidamente auxiliados na tentativa de aprenderem a conviver com as limitações relacionadas a perdas biológicas, como perda de força, de resistência e da acuidade dos sentidos. Para esse autor, as tarefas características da idade adulta avançada consistem, entre outras, em realizar ajustamentos quanto à diminuição de força física e saúde, à aposentadoria e à redução de renda. No caso dos homens idosos, Lunenfeld (2002) destaca a relevância, entre outras medidas, de estabelecer programas de empoderamento para torná-los melhor informados sobre o processo de envelhecimento normal do homem e promover o envelhecimento de um modo mais positivo e ativo. Isso pode favorecer aos homens serem administradores de sua própria saúde, bem como da saúde do seu ambiente social.

Por fim, foi mencionada ainda a importância do cultivo de práticas espirituais e religiosas na velhice, tendo em vista a busca do envelhecimento bem-sucedido: "Aparentemente alguma inclinação religiosa também é uma coisa importante pra algumas pessoas... não digo que traz um maior bem-estar, mas traz um direcionamento" (Paulo, 62 anos).

\section{Considerações finais}

O relato dos idosos entrevistados possibilitou verificar e analisar suas percepções e significações acerca do envelhecimento e da obtenção ou manutenção de saúde na velhice. A dimensão física foi predominantemente apontada como essencial no alcance do envelhecimento bem-sucedido. No entanto, o envelhecimento ideal não foi definido somente pela ausência de perdas físicas, mas também por outras variáveis intervenientes nesse processo, o que indica que a heterogeneidade e a multidimensionalidade do envelhecimento vêm sendo cada vez mais reconhecidas em nossa sociedade. Observaram-se, entre os participantes, perspectivas positivas e visão ampla e apropriada dos cuidados necessários para a preservação da saúde. Problemas em grande parte decorrentes do avanço do envelhecimento, como hipertensão arterial e diminuição do vigor físico, não pareceram impedi-los de exercer autonomia e buscar uma melhor qualidade de vida.
Não obstante o pequeno número de participantes, e ainda que de forma exploratória e sem investigação exaustiva da influência das variáveis sociodemográficas, este estudo trouxe como contribuição a percepção de homens idosos sobre o envelhecer. A perspectiva dos idosos, em associação com as avaliações profissionais, mostra-se importante para o planejamento de estratégias preventivas e de promoção de saúde efetivas e, em decorrência, pode colaborar para a maior eficácia das intervenções desenvolvidas junto a esse grupo etário, bem como para uma revisão das construções sociais associadas à velhice. Por outro lado, seria interessante a condução de novas pesquisas com a finalidade de aprofundar aspectos levantados neste trabalho e para comparar a percepção de homens de diferentes níveis de renda e de escolaridade.

\section{Referências}

Baltes, P. B. (1987). Theorical propositions of life-span developmental psychology: On the dynamics between growth and decline. Developmental Psychology, 23(5), 611-626.

Bardin, L. (2002). Análise de conteúdo (L. A. Reto \& A. Pinheiro, Trads.). Lisboa: Edições 70. (Original publicado em 1977)

Berger, K. S. (2003). O desenvolvimento da pessoa da infância à terceira idade (D. C. Alencar, Trad.). Rio de Janeiro: LTC. (Original publicado em 1983)

Bode, C., \& Ridder, D. T. D. (2007). Investing in the future - identifying participants in an educational program for middle-aged and older adults. Health Education Research, 22(4), 473-482.

Braz, M. (2005). A construção da subjetividade masculina e seu impacto sobre a saúde do homem: Reflexão bioética sobre justiça distributiva. Ciência \& Saúde Coletiva, 10(1), 97-104.

Carmel, S. (2001). The will to live: Gender differences among elderly persons. Social Science \& Medicine, 52(6), 949-958.

Cupertino, A. P. F. B., Rosa, F. H. M., \& Ribeiro, P. C. C. (2007). Definição de envelhecimento saudável na perspectiva de indivíduos idosos. Psicologia: Reflexão e Crítica, 20(1), 81-86.

Figueiredo, M. L. F., Tyrrel, M. A. R., Carvalho, C. M. R. G., Luz, M. H. B. A., Amorim, F. C. M., \& Loiola, N. L. A. (2007). As diferenças de gênero na velhice. Revista Brasileira de Enfermagem, 60(4), 422-427.

Fletcher, R. J., Higginbotham, N., \& Dobson, A. (2002). Men's perceived health needs. Journal of Health Psychology, 7(3), 233-241.

Gomes, R., \& Nascimento, E. R. (2006). A produção do conhecimento da saúde pública sobre a relação homemsaúde: Uma revisão bibliográfica. Cadernos de Saúde Pública, 22(5), 901-911. 
Giffin, K. (2005). A inserção dos homens nos estudos de gênero: Contribuições de um sujeito histórico. Ciência \& Saúde Coletiva, 10(1), 47-57.

Issa, M. M., Fenter, T. C., Black, L., Grogg, A. L., \& Kruep, E. J. (2006). An assessment of the diagnosed prevalence of diseases in men 50 years of age or older. The American Journal of Managed Care, 12(Suppl. 4), 83-89.

Keene, J., \& Li, X. (2005). Age and gender differences in health service utilization. Journal of Public Health, 27(1), 74-79.

Laurenti, R., Jorge, M. H. P. M., \& Gotlieb, S. L. D. (2005). Perfil epidemiológico da morbi-mortalidade masculina. Ciência \& Saúde Coletiva, 10(1), 35-46.

Lunenfeld, B. (2002). The ageing male: Demographics and challenges. World Journal Urology, 20(1), 11-16.

Neri, A. L., Yassuda, M. S., \& Cachioni, M. (2004). Velhice bem sucedida: Aspectos afetivos e cognitivos. Campinas, SP: Papirus.

Peel, N. M., McClure, R. J., \& Bartlett, H. P. (2005). Behavioral determinants of healthy aging. American Journal of Preventive Medicine, 28(3), 298-304.

Ribeiro, P. C. C., Neri, A. L., Cupertino, A. P. F. B., \& Yassuda, M. S. (2009). Variabilidade no envelhecimento ativo segundo gênero, idade e saúde. Psicologia em Estudo, 14(3), 501-509.

Rowe, J. W., \& Kahn, R. L. (1987). Human aging: Usual and successful. Science, 237(4811), 143-149.

Rowe, J. W., \& Kahn, R. L. (1997). Successful aging. The Gerontologist, 37(4), 433-440.

Schneider, R. H., \& Irigaray, T. Q. (2008). O envelhecimento na atualidade: Aspectos cronológicos, biológicos, psicológicos e sociais. Estudos de Psicologia (Campinas), 25(4), 585-593.

Schraiber, L. B., Gomes, R., \& Couto, M. T. (2005). Homens e saúde na pauta da saúde coletiva. Ciência \& Saúde Coletiva, 10(1), 7-17.

Teixeira, I. N. D. O., \& Neri, A. L. (2008). Envelhecimento bem-sucedido: Uma meta no curso da vida. Psicologia USP, 19(1), 81-94.

Veloz, M. C. T., Nascimento-Schulze, C. M., \& Camargo, B. V. (1999). Representações sociais do envelhecimento. Psicologia: Reflexão e Crítica, 12(2), 479-501.

Veras, R. P. (1994). País jovem com cabelos brancos: A saúde do idoso no Brasil. Rio de Janeiro: Relume Dumará.

Veras, R. (2009). Envelhecimento populacional contemporâneo: Demandas, desafios e inovações. Revista de Saúde Pública, 43(3), 548-554.

Witter, G. P. (2006). Tarefas de desenvolvimento do adulto idoso. Estudos de Psicologia (Campinas), 23(1), 13-18.

World Health Organization - WHO. (2005). Envelhecimento ativo: Uma política de saúde (S. Gontijo, Trad.). Brasília: Organização Pan-Americana da Saúde.
Zunzunegui, M. V., Alvarado, B. E., Béland, F., \& Vissandjee, B. (2009). Explaining health differences between men and women in later life: A cross-city comparison in Latin America and the Caribbean. Social Science \& Medicine, 68(2), 235-242.

Lilian Maria Borges Gonzalez é Professora Doutora do Curso de Psicologia da Universidade Católica de Brasília.

Eliane Maria Fleury Seidl é Professora Adjunta do Instituto de Psicologia da Universidade de Brasília.

Recebido: 07/07/2010

$1^{a}$ revisão: $27 / 04 / 2011$

Aceite final: 10/05/2011 